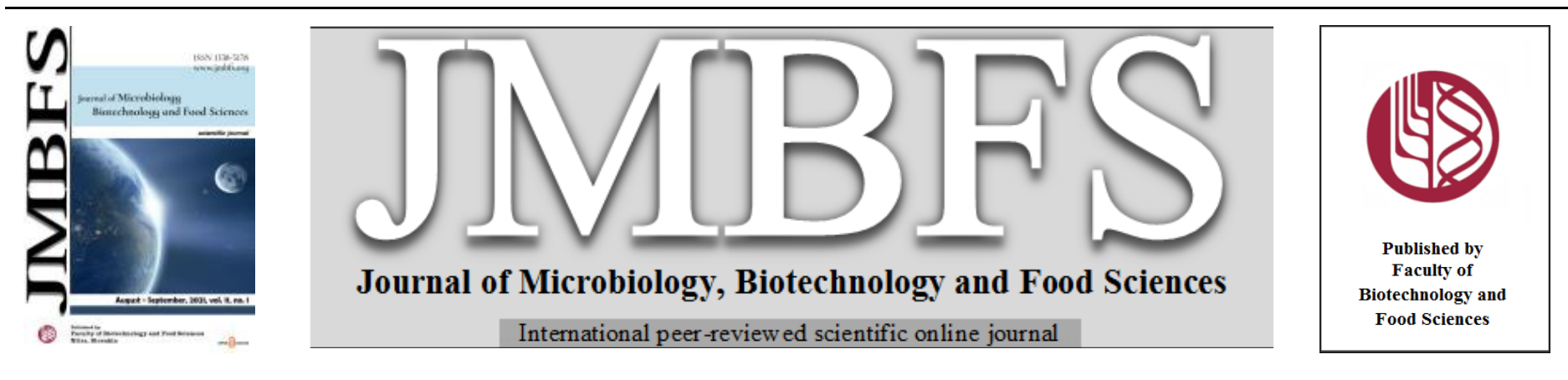

\title{
EVALUATION OF ANTIMICROBIAL POTENTIAL OF DIFFERENT COMMERCIAL GRAPEFRUIT SEED EXTRACTS
}

\author{
Belmina Saric ${ }^{* 1}$, Irma Mahmutović-Dizdarevic ${ }^{2,3}$, Ana Gutalj ${ }^{2}$, Anesa Jerković-Mujkić ${ }^{2}$ \\ Address(es): Belmina Saric, MSc, \\ ${ }^{1}$ University of Sarajevo, Institute for Genetic Engineering and Biotechnology, Zmaja od Bosne 8, 71000 Sarajevo, Bosnia and Herzegovina, +38762600168. \\ ${ }_{2}^{2}$ University of Sarajevo, Faculty of Science, Department of Biology, Laboratory for Microbiology, Zmaja od Bosne 33-35, 71 000 Sarajevo, Bosnia and Herzegovina. \\ ${ }^{3}$ University of Sarajevo, Faculty of Science, Department of Biology, Laboratory for Research and Protection of Endemic Resources, Zmaja od Bosne 33-35, 71 000 \\ Sarajevo, Bosnia and Herzegovina.
}

*Corresponding author: belmina.saric@ingeb.unsa.ba

https://doi.org/10.15414/jmbfs.4213

\section{ARTICLE INFO}

Received 13.1.2021

Revised 16. 2. 2021

Accepted 16. 2. 2021

Published 1. 8. 2021

Regular article

OPEN $\partial_{\text {ACCESS }}$

\begin{abstract}
Extracts made from grapefruit (Citrus x paradisi Macfad.) seed are recognized for strong bactericidal and fungicidal properties. Bacterial resistance to antibiotics is an emerging issue, and therefore isolation and characterization of novel antimicrobials of natural origin represent the real challenge for investigators worldwide. The aim of this study was to evaluate the antimicrobial activity of three commercial GSE (Grapefruit Seed Extract) products against six bacterial and one fungal strain, through the agar well diffusion method, determination of minimum inhibitory concentration (MIC), minimum bactericidal concentration (MBC), and minimum fungicidal concentration (MFC). Obtained results indicate strong antimicrobial effects of investigated extracts, with different microbial susceptibility, including the multidrug-resistant (MDR) bacteria. The highest inhibitory potential is conducted for Citrofit ${ }^{\circledR}$, while

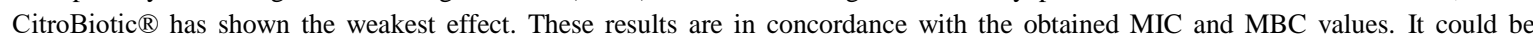
concluded that frequent use of commercial GSEs is justified due to their powerful antimicrobial activity. These findings are promising in terms of utilization of natural products as novel antimicrobial agents.
\end{abstract}

\section{INTRODUCTION}

Antimicrobial resistance is recognized as one of the leading global health problems of 21 st century by all major regulatory, economic and political bodies. Finding the new antimicrobials of natural origin, investigation of their in vitro and in vivo activity, as well as defining their precise chemical composition occupies investigators worldwide during the last decades. Grapefruit (Citrus x paradisi), well known plant from Rutaceae family, is used in traditional medicine as the treatment for different diseases and conditions such as: ulcers, urinary and gastrointestinal infections, cardiovascular diseases, diabetes, cancer, and regulation of body weight and lipid metabolism (Çiçek Polat et al., 2018). Grapefruit seed extract (GSE) is commercial product derived from the seed and pulp of grapefruit (Han et al., 2015), and mainly represent 33\% water-glycerol solution widely used as naturopathic remedy, food supplement, disinfectant and preservative in food and cosmetic industry (Cvetnić \& Vladimir-Knežević, 2004). GSE has powerful antimicrobial properties, including antibacterial, antifungal, antiviral, and antiparasitic activity, and for this reason has attracted much attention from the general public (Reagor et al., 2002; Cvetnić \& Vladimir-Knežević, 2004; Xu et al., 2007; Lim et al., 2010). Main chemical substances responsible for antimicrobial effects of GSEs are polyphenolic compounds such as catechin, epicatechin, epicatechin-3-O-gallate, dimeric, trimeric and tetrameric procyanidins (Aloui et al., 2014). In addition, commercially available GSEs contain some artificial agents such as benzethonium chloride, triclosan and methyl paraben, but investigation of antimicrobial potential of fully natural grapefruit seed extracts has showed that antimicrobial activity could not be attributed only to the synthetic preservative agents (Cvetnić \& Vladimir-Knežević, 2004). GSE as the commercial product

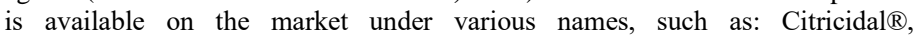
Citrobiotic $\AA$, Citrofit $\AA$, Citrosept $\AA$, NutriBiotic $₫$ and many others. The aim of this study was in vitro examination of antimicrobial activity of three different commercially produced GSEs, and determination of the sensitivity degree of Gram-positive and Gram-negative bacteria and fungi on tested extracts.

\section{MATERIAL AND METHODS}

\section{Investigated microbial strains and extracts}

Antibacterial and antifungal activity of three commercial GSEs: Citrofit ${ }^{\circledR}$ (Vedicon, Austria), CitroBiotic ${ }^{\circledR}$ (Sanitas $\mathrm{GmbH} \&$ Co., Germany), and NutriBiotic GSE Liquid Concentrate ${ }^{\circledR}$ (NutriBiotic, California, USA) is evaluated against following microorganisms: Bacillus subtilis subsp. spizizenii ATCC 6633, Staphylococcus aureus subsp. aureus ATCC 33591 (MRSA strain), Enterococcus faecalis ATCC 29212, Escherichia coli ATCC 35218 (ESBL producing strain), Salmonella enterica subsp. enterica serovar Enteritidis ATCC 13076, Pseudomonas aeruginosa ATCC 9027, and Candida albicans ATCC 10231. According to the manufacturer, Citrofit ${ }^{\circledR}$ contains $33 \%$ of grapefruit seed

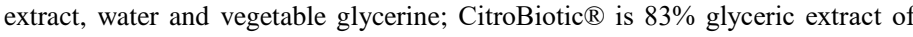
grapefruit seed and peel, combined with water and ascorbic acid. NutriBiotic GSE Liquid Concentrate ${ }^{\circledR}$ contains grapefruit seed extract (33\%) and vegetable glycerine (67\%).

\section{Agar well diffusion method}

Agar well diffusion method is performed according to the Balouiri et al. (2016) Investigated bacterial strains were at first cultured overnight at $37^{\circ} \mathrm{C}$ in Mueller Hinton (MH) medium (HiMedia Laboratories Pvt. Limited, India) and fungal strain in Sabouraund 4\% Glucose Agar (SGA) (Sigma-Aldrich, USA). Following the recommendations of EUCAST (2017), the inoculum was prepared from overnight cultures of test microorganisms in sterile saline solution to obtain a uniform homogeneous turbidity corresponding to the $0.5 \mathrm{McFarland}$ standard, and a microbial cell concentration of $1-2 \times 10^{8} \mathrm{CFU} / \mathrm{ml}$. Inoculation was performed using sterile swabs soaked in a suspension of test microorganisms. After inoculation, the seeded agar plates were left at room temperature for 15 minutes to allow the better absorption of the applied inoculum into the substrate. After the substrate absorbed the inoculum, plates were drilled in order to make wells with diameter of $8 \mathrm{~mm} .50 \mu \mathrm{l}$ of investigated grapefruit seed extracts, were transferred into the wells and incubated for 16 to 18 hours at $37^{\circ} \mathrm{C}$. All extracts 
were triple tested. Antimicrobial activity of tested GSEs was evaluated based on diameter of inhibition zones, after the extract diffusion in the medium. Four different antibiotics: Colistin $(10 \mu \mathrm{g})$, Streptomycin $(10 \mu \mathrm{g})$, Ampicillin $(10 \mu \mathrm{g})$ and Amoxicillin $(25 \mu \mathrm{g})$, as well as standard antifungal drug Nystatin (100 IU), all made by Oxoid ${ }^{\mathrm{TM}}$, Great Britain, were used as positive control.

\section{Broth microdilution method}

Broth microdilution method (CLSI, 2018) was applied in order to determine the minimum inhibitory concentration (MIC) and minimum bactericidal concentration (MBC) of tested grapefruit seed extracts. Considering the antifungal activity, we used the term MFC (minimum fungicidal concentration). Serial dilutions were made in sterile 96 well microtiter plate. Amoxicillin (Sigma-Aldrich, USA) and Nystatin (Sigma-Aldrich, USA) were used as reference, prepared in initial concentration of $1024 \mu \mathrm{g} / \mathrm{ml}$ and $1000 \mu \mathrm{g} / \mathrm{ml}(5916$ IU/ml), respectively. Dimethyl Sulfoxide, DMSO (Sigma-Aldrich, USA) was used as the solvent. At first, $100 \mu \mathrm{L}$ of liquid $\mathrm{MH}$ medium was added to each well in a microtiter plate, except in the wells of the first column. Amount of 200 $\mu 1$ of tested GSEs at initial concentration of $330 \mu \mathrm{g} / \mathrm{ml}$ was added in the firs microtiter column. Then, $100 \mu \mathrm{l}$ of extract was transferred from the first column to the second, and after mixing $100 \mu \mathrm{l}$ of content, transferred from the second to the third column. This procedure was repeated to the tenth column, from which $100 \mu \mathrm{l}$ of content was finally removed. In this way, in each row of the microtiter plate, from position 2 to position 10, a serial two-fold dilution of the test substance in the range of 165 to $0.64 \mu \mathrm{g} / \mathrm{ml}$ was obtained. The last row in the microtiter plate contained double serial dilution of antibiotic, starting from 512 to $2 \mu \mathrm{g} / \mathrm{ml}$. Wells from the second to the eleventh column were then inoculated with the $5 \mu \mathrm{l}$ of test microorganisms' suspension, at the concentration of $1-2 \times 10^{8}$ $\mathrm{CFU} / \mathrm{ml}$, and final concentration of $5 \times 10^{5} \mathrm{CFU} / \mathrm{ml}$ was obtained. Column 11 containing $100 \mu \mathrm{l}$ of standard inoculum without tested GSEs served as the positive control, while column 12 containing only the sterile liquid medium and DMSO was used as the negative control. Each test was performed twice. Microtiter plates were incubated for $16-18$ hours at $37^{\circ} \mathrm{C}$.

\section{Resazurin assay}

Reading of MIC is done manually using an inverted mirror and after that $30 \mu \mathrm{l}$ of 0.015\% Resazurin sodium salt solution (Sigma-Aldrich, USA) was added to all wells. Resazurin dye allows easier interpretation of the results (Elshikh $\boldsymbol{e t}$ al. 2016). The wells containing the living microorganisms were coloured pink, while those with death microorganisms, destroyed by the test substance, were stained blue. All columns with no visible colour change represent the concentration of the extract above the MIC value. The last position in the row where the blue colour remained, while there is a presence of pink colour in the next position, represents MIC

\section{Minimum bactericidal concentration (MBC) and minimum antifungal concentration (MFC) assays}

After the determining of minimum inhibitory concentration (MIC), the determination of the minimum bactericidal concentration (MBC) and minimum fungicidal concentration (MFC) was proceeded (CLSI, 2018). The volume of 10 $\mu 1$ of content from the well whose position was marked as MIC, as well as from the previous three wells in the same row with no observed microbial growth, was transferred on agar plates with $\mathrm{MH} / \mathrm{SGA}$ medium. Inoculated plates were incubated at $37{ }^{\circ} \mathrm{C}$ for $18-24$ hours. The MBC/MFC was recorded as the value closest to the determined MIC value, at which there was no growth of microorganisms after incubation. All experiments were performed in triplicate.

\section{Statistical analysis}

Performed tests were done in three replications, therefore descriptive statistical parameters: mean values \pm standard deviation (SD) were calculated, using the Microsoft Office 2019 Excel (Microsoft Corporation, USA). In order to determine the presence of statistically significant differences between collected data, One-way ANOVA and post hoc Fisher's Least Significant Difference (LSD) test (STATISTICA 10; StatSoft.Inc.) were applied, at the significance level of $\mathrm{p}<0.05$.

\section{RESULTS AND DISCUSSION}

\section{Antibacterial and antifungal assays}

All three investigated GSEs showed inhibitory effects against reference

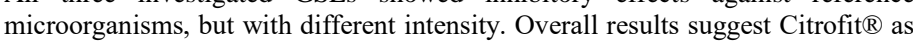
the strongest GSE, with widest inhibition zones observed in the case of $B$. subtilis subsp. spizizenii $(31.00 \pm 0.00)$ and MRSA (30.00 \pm 0.00$)$. The most sensitive Gram-negative strain to this extract was $S$. enterica subsp. enterica serovar Enteritidis (24.30 \pm 1.15$)$. Citrofit ${ }^{\circledR}$ caused the greatest inhibition of $C$. albicans $(26.30 \pm 0.57)$ as well, which is significantly different in comparison to the standard antimycotic (Tab 1). These results are in accordance with the investigation of Krajewska-Kulak et al. (2003), where 33\% grapefruit-water glycerol solution also exhibited strong activity against the yeast-like fungi NutriBiotic ${ }^{\circledR}$ performed balanced antibacterial activity, with the greatest zones on $P$. aeruginosa $(25.30 \pm 1.52)$, followed by slightly different inhibition of multidrug-resistant ESBL producing E. coli $(25.00 \pm 1.00)$, MRSA, E. faecalis, $S$ enterica subsp. enterica serovar Enteritidis (24.60 \pm 0.57$)$, and B. subtilis subsp.

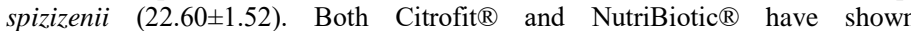
significantly higher antibacterial and antifungal activity compared to the CitroBiotic $($ (Tab 1). A possible explanation for such results could be the fact that CitroBiotic ${ }^{\circledR}$ preparation is completely free of benzethonium chloride, benzalkonium chloride and triclosan, as well as of organochlorine- and organophosphorus-pesticides (Manufacturer Report No. K 2465 FN - III and K $2465 \mathrm{FN}-\mathrm{I})$. There is a chance that some of the listed substances may act as antimicrobial agents. Statistical analysis has shown that antimicrobial activity of tested GSEs was significantly higher from antibacterial and antifungal effects of tested antimicrobials (Tab 1). None of four used antibiotics didn't cause inhibition of MRSA, in contrast to the effects of GSEs. The obtained results coincide with the data that GSE has a pronounced effect on methicillin-resistant Staphylococcus aureus (Su et al., 2012), which indicates that investigated extract could be used in the treatment of infections caused by this multiresistant bacterial strain. In addition, ESBL producing E. coli was inhibited by Colistin and Streptomycin, but with lower rate in comparison to the GSEs (Tab 1). In most cases, Gram-positive bacteria have shown greater sensitivity to the investigated extracts compared with Gram-negative bacteria, which is in line with previous findings (Reagor et al., 2002; Heggers et al., 2004; Xu et al., 2007; Bangwoo et al., 2015). This could be explained by the fact that Gram-positive bacteria have only a thick layer of peptidoglycan in their cell wall, which makes them susceptible to inhibitory substances, while Gram-negative bacteria have an outer lipid membrane in their cell wall, as a kind of barrier, making them less sensitive. GSE probably acts by destroying the cell membrane and ultimately leading to lysis and death of the bacterium (Heggers et al., 2004; Bhatia et al., 2015).

Table 1 Diameter of inhibition zones* (mm) obtained through the agar well diffusion method

\begin{tabular}{|c|c|c|c|c|c|c|c|c|}
\hline \multirow{2}{*}{ Microbes } & \multicolumn{3}{|c|}{ Investigated GSEs } & \multicolumn{5}{|c|}{ Standard antimicrobials } \\
\hline & Citrofit ${ }^{\circledR}$ & CitroBiotic ${ }$ & NutriBiotic ${ }^{\circledR}$ & Colistin & Streptomycin & Ampicillin & Amoxicillin & Nystatin \\
\hline $\begin{array}{l}\text { Bacillus subtilis subsp. spizizenii ATCC } \\
6633\end{array}$ & $31.00 \pm 0.00^{\mathrm{a}}$ & $18.50 \pm 0.57^{\mathrm{c}}$ & $22.60 \pm 1.52^{\mathrm{a}}$ & $10 \pm 0.00^{\mathrm{b}}$ & $20 \pm 0.00^{\mathrm{d}}$ & $22 \pm 0.00^{\mathrm{b}, \mathrm{e}}$ & $25 \pm 0.00^{\mathrm{b}, \mathrm{d}}$ & - \\
\hline $\begin{array}{l}\text { Staphylococcus aureus subsp. } \\
\text { aureus ATCC } 33591 \text { (MRSA strain) }\end{array}$ & $30.00 \pm 0.00^{\mathrm{a}}$ & $12.00 \pm 0.00^{\mathrm{c}}$ & $24.60 \pm 0.57^{\mathrm{a}}$ & NI & NI & NI & NI & - \\
\hline Enterococcus faecalis ATCC 29212 & $28.00 \pm 0.00^{\mathrm{a}}$ & $15.60 \pm 2.08^{\mathrm{c}}$ & $24.30 \pm 0.57^{\mathrm{a}}$ & $\mathrm{NI}$ & $15 \pm 0.00^{\mathrm{d}}$ & $9 \pm 0.00^{\mathrm{b}, \mathrm{e}}$ & NI & - \\
\hline $\begin{array}{l}\text { Escherichia coli ATCC } 35218 \\
\text { (ESBL producing strain) }\end{array}$ & $21.60 \pm 0.57^{\mathrm{a}}$ & $14.00 \pm 0.00^{c}$ & $25.00 \pm 1.00^{\mathrm{a}}$ & $10 \pm 0.00^{\mathrm{b}}$ & $12 \pm 0.00^{\mathrm{d}}$ & NI & NI & - \\
\hline $\begin{array}{l}\text { Salmonella enterica subsp. entericaserovar } \\
\text { Enteritidis ATCC } 13076\end{array}$ & $24.30 \pm 1.15^{\mathrm{a}}$ & $16.30 \pm 1.15^{\mathrm{c}}$ & $24.60 \pm 0.57^{\mathrm{a}}$ & $11 \pm 0.00^{\mathrm{b}}$ & $15 \pm 0.00^{\mathrm{d}}$ & NI & $18 \pm 0.00^{\mathrm{b}, \mathrm{d}}$ & - \\
\hline Pseudomonas aeruginosa ATCC 9027 & $18.30 \pm 0.57^{\mathrm{a}}$ & $12.50 \pm 0.50^{\mathrm{c}}$ & $25.30 \pm 1.52^{\mathrm{a}}$ & $17 \pm 0.00^{\mathrm{b}}$ & $14 \pm 0.00^{\mathrm{d}}$ & NI & NI & - \\
\hline Candida albicans ATCC 10231 & $26.30 \pm 0.57^{\mathrm{a}}$ & $13.30 \pm 0.57^{\mathrm{C}}$ & $15.60 \pm 0.57^{\mathrm{a}}$ & - & - & - & - & $20.60 \pm 1.15$ \\
\hline
\end{tabular}

*Results are Mean \pm SD

$\mathrm{NI}=$ No inhibition

Columns that don't share the same letters, differ significantly at $\mathrm{p}<0.05$ after post hoc LSD test. 


\section{Determination of minimum inhibitory concentration (MIC)}

In terms of antibacterial and antifungal activity, tested GSEs have showed MIC values of $<0.64-82.50 \mu \mathrm{g} / \mathrm{ml}$ (Tab 2). Comparing the three GSEs used in this investigation, Citrofit ${ }^{\circledR}$ has showed a higher antimicrobial activity than CitroBiotic $\AA$ and NutriBiotic $®$. Furthermore, antimicrobial activity of this extract almost completely surpassed the activity of Amoxicillin and Nystatin Tested antibiotic didn't cause the growth inhibition of MRSA, E. faecalis and ESBL producing $E$. coli, while all tested extracts were successful in this sense (Tab 2).

Table 2 Minimum inhibitory concentration (MIC) of tested extracts and controls

\begin{tabular}{|c|c|c|c|c|}
\hline \multirow{2}{*}{ Microbes } & \multicolumn{3}{|c|}{ MIC* $(\mu \mathrm{g} / \mathrm{ml})$ of GSEs } & \multirow{2}{*}{ Control $(\mu \mathrm{g} / \mathrm{ml})$} \\
\hline & Citrofit ${ }^{\circledR}$ & CitroBiotic ${ }^{\circledR}$ & NutriBiotic ${ }^{\circledR}$ & \\
\hline $\begin{array}{l}\text { Bacillus subtilis subsp. spizizenii } \\
\text { ATCC } 6633\end{array}$ & $<0.64$ & 82.50 & 41.25 & $8.00^{1}$ \\
\hline $\begin{array}{l}\text { Staphylococcus aureus subsp. } \\
\text { aureus ATCC } 33591 \text { (MRSA strain) }\end{array}$ & $<0.64$ & 10.32 & 5.16 & $\mathrm{NI}^{1}$ \\
\hline Enterococcus faecalis ATCC 29212 & 20.63 & 20.63 & 20.63 & $\mathrm{NI}^{1}$ \\
\hline $\begin{array}{l}\text { Escherichia coli ATCC } 35218 \\
\text { (ESBL producing strain) }\end{array}$ & 20.63 & 20.63 & 20.63 & $\mathrm{NI}^{1}$ \\
\hline $\begin{array}{l}\text { Salmonella enterica subsp. enterica } \text { serovar } \\
\text { Enteritidis ATCC } 13076\end{array}$ & 10.32 & 20.63 & 41.25 & $256.00^{1}$ \\
\hline Pseudomonas aeruginosa ATCC 9027 & $<0.64$ & 10.32 & 2.58 & $\mathrm{NI}^{1}$ \\
\hline Candida albicans ATCC 10231 & $<0.64$ & 82.50 & 41.25 & $7.81^{2}$ \\
\hline
\end{tabular}

${ }^{*}$ Same values obtained through the duplicate.

${ }^{1}$ Amoxicillin, initial concentration $1024 \mu \mathrm{g} / \mathrm{ml}$

${ }^{2}$ Nystatin, initial concentration $1000 \mu \mathrm{g} / \mathrm{ml}(5916 \mathrm{IU} / \mathrm{ml})$

$\mathrm{NI}=$ No inhibition

\section{Determination of MBC and MFC}

The microdilution method of testing the minimum inhibitory concentration of Citrofit ${ }^{\circledR}$ has showed the most effective action on four microorganisms $(B$. subtilis, MRSA, P. aeruginosa, and C. albicans) with the MIC less than 0.64 $\mu \mathrm{g} / \mathrm{ml}$, whereby Gram-positive bacteria were more susceptible than Gramnegative. The same results were observed in the study of the minimum bactericidal and minimum fungicidal concentration following the results of the MIC, where Citrofit ${ }^{\circledR}$ had the strongest effect (Tab 2, Tab 3).

Table 3 Minimum bactericidal concentration (MBC) and minimum fungicidal concentration (MFC)

\begin{tabular}{|c|c|c|c|c|}
\hline \multirow{2}{*}{ Microbes } & \multicolumn{3}{|c|}{ MBC and MFC* $(\mu \mathrm{g} / \mathrm{ml})$ of GSEs } & \multirow{2}{*}{ Control $(\mu \mathrm{g} / \mathrm{ml})$} \\
\hline & Citrofit ${ }^{\circledR}$ & CitroBiotic ${ }^{\circledR}$ & NutriBiotic ${ }^{\circledR}$ & \\
\hline $\begin{array}{l}\text { Bacillus subtilis subsp. spizizenii } \\
\text { ATCC } 6633\end{array}$ & $<0.64$ & 165.00 & 82.50 & $16.00^{1}$ \\
\hline $\begin{array}{l}\text { Staphylococcus aureus subsp. } \\
\text { aureus ATCC } 33591 \text { (MRSA strain) }\end{array}$ & $<0.64$ & 20.64 & 10.32 & $\mathrm{NI}^{1}$ \\
\hline Enterococcus faecalis ATCC 29212 & 41.26 & 41.26 & 41.26 & $\mathrm{NI}^{1}$ \\
\hline $\begin{array}{l}\text { Escherichia coli ATCC } 35218 \\
\text { (ESBL producing strain) }\end{array}$ & 41.26 & 41.26 & 41.26 & $\mathrm{NI}^{1}$ \\
\hline $\begin{array}{l}\text { Salmonella enterica subsp. enterica serovar } \\
\text { Enteritidis ATCC } 13076\end{array}$ & 20.64 & 41.26 & 82.50 & $512^{1}$ \\
\hline Pseudomonas aeruginosa ATCC 9027 & $<0.64$ & 20.64 & 5.16 & $\mathrm{NI}^{1}$ \\
\hline Candida albicans ATCC 10231 & $<0.64$ & 165.00 & 82.50 & $15.62^{2}$ \\
\hline \multicolumn{5}{|c|}{$\begin{array}{l}{ }^{3} \text { Same values obtained through the triplicate. } \\
{ }^{1} \text { Amoxicillin, initial concentration } 1024 \mu \mathrm{g} / \mathrm{ml} \\
{ }^{2} \text { Nystatin, initial concentration } 1000 \mu \mathrm{g} / \mathrm{ml}(5916 \mathrm{IU} / \mathrm{ml}) \\
\text { NI=No inhibition }\end{array}$} \\
\hline
\end{tabular}

\section{CONCLUSION}

Commercial GSEs investigated in this study have shown antimicrobial activity against all tested Gram-positive and Gram-negative bacteria, as well as the strain of pathogenic fungus $C$. albicans. The strongest inhibitory effects were observed for Citrofit ${ }^{\circledR}$, especially against multidrug-resistant pathogens (MRSA and ESBL E. coli). Tested antimicrobials proved to be less effective against bacteria and $C$. albicans strain in comparison to the GSEs. There are differences between the antimicrobial activity of each extract, which could be attributed to the chemical content variation. It is known that phytochemical profile, as well as biological activity of plant products, could be related to the specific abiotic factors in the plant habitat, but also the conditions of mass production process. Also, there is a possibility that artificial additives, frequently present in such extracts, could be related to overall antimicrobial potential. It is promising that commercially available products of natural origin, possess such remarkable antimicrobia activity, especially in times where most synthetic antibiotics are less and less effective. However, it must be noted that investigated extracts could represent a dietary supplement and not an official treatment against infectious diseases. Wider medicinal use of GSEs should be supported with exact evidence regarding its phytochemicals, pharmacological and biological properties.

\section{REFERENCES}

Aloui, H., Khwaldia, K., Sánchez-González, L., Muneret, L., Jeandel, C., Hamdi, M., \& Desobry, S. (2014). Alginate coatings containing grapefruit essential oil or grapefruit seed extract for grapes preservation. International Journal of Food Science \& Technology, 49(4), 952-959. https://doi.org/10.1111/ijfs.12387

Balouiri, M., Sadiki, M., \& Ibnsouda, S. K. (2016). Methods for in vitro evaluating antimicrobial activity: A review. Journal of Pharmaceutical Analysis, 6(2), 71-79. https://doi.org/10.1016/j.jpha.2015.11.005

Bangwoo, H., Ji-Soo, K., Hak-Joon, K., Chang-Gyu, W., \& Yong-Jin, K. (2015) Investigation of Antimicrobial Activity of Grapefruit Seed Extract and ItsApplication to Air Filters with Comparison to Propolis and Shiitake. Aerosol and Air Quality Research, 15, 1035-1044 http://dx.doi.org/10.4209/aaqr.2014.09.0208

Bhatia, S., Garg, S., \& Kumari, A. (2015). EVALUATING THE EFFICACY OF EDTA, GRAPEFRUIT SEED EXTRACT, LYSOZYME AND SODIUM BENZOATE INCORPORATED IN STARCH-GLYCEROL BASED ANTIMICROBIAL FOOD PACKAGING FILM. Journal of Microbiology, Biotechnology and Food Sciences, 5 (2) 120-126. https://doi.org/10.15414/jmbfs.2015.5.2.120-126

Çiçek Polat, D.C., Eyılmaz, M., Akalın, K., \& Coskun, M. (2018). Antimicrobial Activity of Grapefruit Seed. Hacettepe University Journal of the Faculty of Pharmacy, 38(1), https://dergipark.org.tr/tr/pub/hujpharm/issue/38887/453947 
CLSI (CLINICAL AND LABORATORY STANDARDS INSTITUTE) (2018). MO7: Methods for Dilution Antimicrobial Susceptibility Test for Bacteria That Grow Aerobically, $11^{\text {th }}$ Edition. https://clsi.org/standards/products/microbiology/documents/m07/

Cvetnić, Z., \& Vladimir-Knežević, S. (2004). Antimicrobial activity of grapefruit seed and pulp ethanolic extract. Acta Pharmaceutica, 54, 243-250. PMID: 15610620

Elshikh, M., Ahmed, S., Funston, S., Dunlop, P., McGaw, M., Marchant, R., \& Banat, I. M. (2016). Resazurin-based 96-well plate microdilution method for the determination of minimum inhibitory concentration of biosurfactants. Biotechnology Letters, 38(6), 1015-1019. https://doi.org/10.1007/s10529-0162079-2

European Committee on Antimicrobial Susceptibility Testing. (2017). EUCAST guidelines for detection of resistance mechanisms and specific resistances of clinical and/or epidemiological importance. EUCAST, Basel, Switzerland:

https://www.eucast.org/fileadmin/src/media/PDFs/EUCAST_files/Resistance_me chanisms/EUCAST_detection_of_resistance_mechanisms_170711.pdf

Han, B., Kang, J., Kim, H., Woo, C., \& Kim, Y. (2015). Investigation of Antimicrobial Activity of Grapefruit Seed Extract and Its Application to Air Filters with Comparison to Propolis and Shiitake. Aerosol and Air Quality Research, 15, 1035-1044. http://dx.doi.org/10.4209/aaqr.2014.09.0208

Heggers, J. P., Cottingham, J., Gusman, J., Reagor, L., McCoy, L., Carino, E., Cox, R., \& Zhao, J-G. (2004). The Effectiveness of Processed Grapefruit-Seed Extract as An Antibacterial Agent: II. Mechanism of Action and In Vitro Toxicity. The Journal of Alternative and Complementary Medicine, 8(3), 333340. https://doi.org/10.1089/10755530260128023

Krajewska-Kulak, E., Lukaszuk, C., \& Niczyporuk, W. (2003). Antifungal activity of $33 \%$ grapefruit-water glycerol solution. Journal of the European Academy of Dermatology and Venereology, 17, 486-487. https://doi.org/10.1046/j.1468-3083.2003.00614 12.x

Lim, G-O., Jang, S-A., \& Song, K. B. (2010). Physical and antimicrobial properties of Gelidium corneum/nano-clay composite film containing grapefruit seed extract or thymol. Journal of Food Engineering, 98(4), 415-420. https://doi.org/10.1016/j.jfoodeng.2010.01.021

Reagor, L., Gusman, J., McCoy, L., Carino, E., \& Heggers, J.P. (2002). The effectiveness of processed grapefruit-seed extract as an antibacterial agent: I. An in vitro agar assay. The Journal of Alternative and Complementary Medicine, 8(3), 325-332. https://doi.org/10.1089/10755530260128014

Su, X., Howell, A.B., \& D'Souza, D.H. (2012). Antibacterial Effects of PlantDerived Extracts on Methicillin-Resistant Staphylococcus aureus. Foodborne Pathogens and Disease, 9(6), 573-578. https://doi.org/10.1089/fpd.2011.1046 Xu, W., Qu, W., Huang, K., Guo, F., Yang, J., Zhao, H., YunBo, L. (2007) Antibacterial effect of Grapefruit Seed Extract on food-borne pathogens and its application in the preservation of minimally processed vegetables. Postharvest
and Technology,
$45(1)$,
126-133.

https://doi.org/10.1016/j.postharvbio.2006.11.019 